\title{
AGRONEGÓCIO E PERSPECTIVAS TEÓRICAS E EPISTÊMICAS: UMA ANÁLISE NOS PROGRAMAS DE PÓS-GRADUAÇÃo EM ADMINISTRAÇÃo
}

AGRIBUSINESS AND THEORECTICAL AND EPISTEMIC PERSPECTIVES: AN

ANALISYS IN THE GRADUATE PROGRAMS IN BUSINESS

Recebimento: 24/10/2017- Aceite: 10/11/2017- Publicação: 28/01/2018

Processo de Avaliação: Double Blind Review

Andressa Scheibeler ${ }^{1}$

Mestranda em Administração

Universidade Federal do Mato Grosso do Sul

andressa.sche@gmail.com

Gabriel Mello

Mestranda em Administração

Universidade Federal do Mato Grosso do Sul

mellosgabriel@gmail.com

Elcio Gustavo Benini

Doutor em Educação

Docente da Universidade Federal do Mato Grosso do Sul

elciobenini@yahoo.com.br

Marcia Maria dos Santos Bortolocci Espejo

Doutora em Controladoria e Contabilidade

Docente da Universidade Federal do Mato Grosso do Sul

marcia.bortolocci@ufms.br

\section{RESUMO}

O objetivo foi identificar os enfoques teórico-metodológicos e epistemológicos empregados na dissertações e teses desenvolvidas entre 2005 e 2015, utilizando como campo empírico de investigação os Programas de Pós-graduação em Administração com linhas de pesquisa em agronegócio no Brasil. Especificamente, o artigo procurou caracterizar as teorias, metodologias e temáticas utilizadas na elaboração dessas pesquisas com base nos estudo de Reed (1999) e Paula (2016). Para tanto, o estudo possui uma abordagem qualitativa, de objetivo exploratório, e como técnica de aproximação se caracteriza como bibliográfica e documental. O resultado mostrou a presença de um grande número de dissertações que possui uma abordagem pautada na metanarrativa mercado, enquadrada na matriz empírico-analítica a partir do círculo de matrizes epistêmicas; a principal abordagem metodológica utilizada é a qualitativa, com finalidade exploratória; a temática mais abordada pelas pesquisas é a de desenvolvimento, envolvendo o

\footnotetext{
1 Autor para correspondência: Universidade Federal do Mato Grosso do Sul - UFMS. Av. Costa e Silva, $\mathrm{s} / \mathrm{n}^{\circ}$ | Bairro Universitário, Campo Grande - MS. 79070-900, Brasil.
}

Revista ENIAC Pesquisa, Guarulhos (SP), V.7, n.1, jan.- jun. 2018. 
desenvolvimento sustentável, local, rural, regional e econômico. Chega-se à conclusão que a temática, os enfoques teóricos e a abertura de novos Programas de Pós-Graduação nessa linha de pesquisa são condizentes com o atual estágio de crescimento do agronegócio do país.

Palavras-chave: Teoria organizacional; Agronegócio; Pós-graduação em Administração.

\section{ABSTRACT}

Theobjective was to identify the theoretical-methodological and epistemological approaches employed in the dissertation and theses developed between 2005 and 2015, in Posgraduate Programs in Administration with lines of research in agribusiness in Brazil. Specifically, the article sought to characterize theories, methodologies and themes used to elaborate these researches based on the previous study of both Reed (1999) and Paula (2016). For this, the study has a qualitative approach, of exploratory objective, and as an approach technique, it is characterized as bibliographical and documentary. The resultshowed a large number of dissertations that had an approach based on the market metanarrative, framed in the empirical-analytic matrix from the circle of epistemic matrices; the main methodological approach is qualitative, with exploratory purpose; the most discussed theme is development, involving sustainable, local, rural, regional and economic development. It is concluded that the theme, the theoretical approaches and the opening of new Posgraduate Programs in this line of research are consistent with the current stage of growth of the country's agribusiness.

Keywords: Organization theory; Agribusiness; Postgraduate in administration.

\section{INTRODUÇÃO}

As teorias organizacionais e as bases espistemológicas são de extrema relevância para dar sustentação às pesquisas empíricas. Tartuce (2006) afirma que o conhecimento humano é formado a partir do senso comum - que é estruturado no mundo empírico - até ser transformado em um conteúdo elaborado, que pode solucionar problemas de forma sistemática e com rigor metodológico, que compõe o proceder científico.

Pensadores do século XIX, como Saint-Simon, tentaram analisar as transformações ideológicas e estruturais ocasionadas pelo capitalismo industrial, levando à origem dos estudos organizacionais (WOLIN, 1961). Dessa forma, diversas teorias foram formadas, que podem ser divididas em metanarrativas de acordo com a contextualização social e histórica, ideias teóricas, condições de estrutura e novos conceitos (REED, 1999).

Reed (1999), em “Teorização Organizacional: um campo historicamente contestado", apresenta uma distinção entre as metanarrativas, problemáticas centrais, e suas principais teorias. Propõe, portanto, diferentes perpectivas teóricas de cunho

Revista ENIAC Pesquisa, Guarulhos (SP), V.7, n.1, jan.- jun. 2018. 
organizacional, que leva às investigações a caminharem por uma das vertentes, e assim, permite que pesquisas empíricas sejam sustentadas por bases teóricas.

Não obstante as contribuições de Reed sobre teorias e metanarrativas sejam elucidativas, é possível observar, já na década de 1970, pesquisas densas com finalidade e natureza epistêmicas. Com efeito, Burrel e Morgan (1979), inspirados em Thomas Kuhn (1969), em texto que veio a se tornar seminal nos estudos organizacionais, apresentaram um modelo composto por paradigmas sociológicos que tem sido alvo de grandes debates. Enquanto desencadeamento desse processo, Paula (2016), por sua vez, ao criticar o modelo de Burrel e Morgan, respaldando-se em Habermas (1968/1982), propôs um modelo de análise epistêmica que conceituou de Círculos de Matrizes Epistêmicas, cuja finalidade seria abarcar zonas de intersecção entre paradigmas e, assim. demonstrar o terreno infértil, gerador de guerras paradigmáticas, que tem permeado os estudos organizacionais (JACKSON; CARTER, 1993).

No âmbito das pesquisas e estudos organizacionais no Brasil, é possível observar nos Programas de Pós-Graduação, na área de Administração, o crescimento de pesquisas direcionadas ao agronegócio, fato relacionado à importância relativa deste setor no país. Com efeito, o agronegócio é responsável por $51,50 \%$ das exportações brasileira, totalizando US\$ 8,64 bilhões, e responsável por 21,46\% do PIB brasileiro segundo dados de 2015 (BRASIL, 2015; CEPEA, 2016).

Segundo Rodrigues (2006), o país possui 22\% das terras agricultáveis do mundo, além de elevada tecnologia utilizada no campo, dados estes que fazem do agronegócio brasileiro um setor moderno, eficiente e competitivo no cenário internacional. Sendo assim, maperar e compreender as bases teóricas-metodológicas e suas respectivas bases epistêmicas é fundamental para o avanço do conhecimento nesse setor.

Diante do exposto surge a seguinte questão de pesquisa: Quais as perspectivas teóricas, metodológicas e espistêmicas empregadas nas dissertações e teses nas linhas de pesquisa ligadas ao agronegócio nos Programas de Pós-graduação em Administração no Brasil? Dessa forma, o artigo possui como objetivo identificar os enfoques teóricometodológicos e epistemológicos empregados nas dissertações e teses desenvolvidas entre 2005 e 2015 em Programas de Pós-graduação em Administração com linhas de pesquisa em agronegócio no Brasil. Especificamente, o artigo procura caracterizar as categorias teóricas e metodológicas utilizadas na elaboração dessas pesquisas.

Revista ENIAC Pesquisa, Guarulhos (SP), V.7, n.1, jan.- jun. 2018. 
O presente artigo justifica-se por oferecer uma contribuição teórica aos estudos organizacionais, designadamente com foco no agronegócio, ao evidenciar um avanço ao contemplar as bases teóricas e epistêmicas como ponto central de reflexão. Essa reflexão teórica e epistemológica é de grande relevância por dar embasamento sólido à realização de pesquisas empíricas na área, e por ainda não haver na literatura uma pesquisa visando identificar as teorias organizacionais empregadas para o desenvolvimento de dissertações e teses de Pós-graduação em Administração que possua como linha de pesquisa o agronegócio.

Com o intuito de construir uma ordem lógica à exposição da pesquisa, a próxima seção apresenta as bases teórico-metodológicas lançadas por Reed (1999) - teorias e metanarrativas - e de Paula (2016) - bases epistêmicas - para dar sustenção na análise. Logo em seguida, a metodologia utilizada é exposta, mostrando como foram delimitados os Programas de Pós-graduação de Administração, com pesquisas direcionadas ao agronegócio, assim como o material empírico analisado - teses e dissertações. A seguir, as metanarrativas encontradas, de acordo com a teoria de Michael Reed, e as bases epistêmicas de Ana Paula Paes de Paula são apresentadas e analisadas, assim como as tipologias e metodologias utilizadas. Por fim, as conclusões finais sobre o tema abordado são descritas.

\section{A TEORIZAÇÃO EM ESTUDOS ORGANIZACIONAIS: TEORIAS, METANARRATIVAS E ORIENTAÇÕES EPISTÊMICAS}

De acordo com Wolin (1961), Saint-Simon introduziu a organização como forma de poder, um novo modo de organização da sociedade em que a ordem seria estabelecida por princípios científicos, independente da subjetividade humana. Para o autor, a organização seria o meio de transformar as irracionalidades humanas em comportamentos racionais.

Reed (1999) afirma que o desenvolvimento de uma sociedade organizacional faria com que a razão, liberdade e justiça avançassem ao mesmo tempo em que possibilitaria erradicar a ignorância, coerção e fraqueza. A organização tinha como símbolo o poder, e era um método de controle social, pois imporia à sociedade a ordem, estrutura e uniformização (WOLIN, 1961).

Revista ENIAC Pesquisa, Guarulhos (SP), V.7, n.1, jan.- jun. 2018. 
As primeiras metanarrativas sobre organização racional foram fragmentadas e dispersas, sem força moral ou coerência analítica (REED, 1992). Entre os anos 1950 e 1960, foram publicados textos que demonstravam segurança na identidade intelectual e racionalidade de seu estudo (ARGYRIS, 1964; BLAU; SCOTT, 1963; HAIRE, 1960), ao passo que nos anos 80 e 90 há, na natureza e no mérito dos textos sobre organizações, perspectivas incertas, complexas e confusas.

Reed (1992) passa a recontar a história da teoria organizacional por meio de relatos analíticos e discursos éticos que determinaram seu desenvolvimento e validaram sua essência, balanceando contexto social e histórico, ideias teóricas e inovação conceitual. Confome o Quadro 1, o autor chega a seis modelos interpretativos de análise.

Quadro 1: Narrativas analíticas em análise organizacional.

\begin{tabular}{|c|c|c|c|c|}
\hline $\begin{array}{c}\text { Modelo de } \\
\text { narrativa } \\
\text { interpretativa } \\
\end{array}$ & $\begin{array}{c}\text { Problemática } \\
\text { central }\end{array}$ & $\begin{array}{c}\text { Perspectivas } \\
\text { ilustrativas/exemplos }\end{array}$ & $\begin{array}{l}\text { Transições } \\
\text { contextuais }\end{array}$ & $\begin{array}{l}\text { Principais } \\
\text { autores }\end{array}$ \\
\hline Racionalidade & Ordem & $\begin{array}{c}\text { Teoria da Organização } \\
\text { clássica, administração } \\
\text { científica, teoria da decisão }\end{array}$ & $\begin{array}{c}\text { De Estado } \\
\text { guarda-noturno a } \\
\text { Estado Industrial }\end{array}$ & $\begin{array}{l}\text { Taylor, Fayol, } \\
\text { Simon }\end{array}$ \\
\hline Integração & Consenso & $\begin{array}{l}\text { Relações Humanas, neo-RH, } \\
\text { funcionalismo, teoria da } \\
\text { contingência/sistêmica, cultura } \\
\text { corporativa }\end{array}$ & $\begin{array}{l}\text { De capitalismo } \\
\text { empresarial a } \\
\text { capitalismo do } \\
\text { bem-estar }\end{array}$ & $\begin{array}{l}\text { Durkhein, } \\
\text { Barnard, Mayo, } \\
\text { Parsons }\end{array}$ \\
\hline Mercado & Liberdade & $\begin{array}{l}\text { Teoria da firma, economia } \\
\text { institucional, custos de } \\
\text { transação, teoria da atuação, } \\
\text { dependência de recursos, } \\
\text { ecologia populacional, teoria } \\
\text { organizacional liberal }\end{array}$ & $\begin{array}{l}\text { De capitalismo } \\
\text { gerencial a } \\
\text { capitalismo } \\
\text { neoliberal }\end{array}$ & $\begin{array}{c}\text { Coase, } \\
\text { Thorstein } \\
\text { Veblen, John } \\
\text { Commons, } \\
\text { Wesley Mitchell }\end{array}$ \\
\hline Poder & Dominação & $\begin{array}{l}\text { Weberianos neo-radicais, } \\
\text { marxismo crítico-estrutural, } \\
\text { processo de trabalho, teoria } \\
\text { institucional }\end{array}$ & $\begin{array}{l}\text { De coletivismo } \\
\text { liberal a } \\
\text { corporativismo } \\
\text { negociado }\end{array}$ & $\begin{array}{l}\text { Weber, Marx, } \\
\text { Meyer, Rowan }\end{array}$ \\
\hline Conhecimento & Controle & $\begin{array}{l}\text { Etnométodo, símbolo/cultura, } \\
\text { pós-estruturalista, pós- } \\
\text { industrialista, pós- } \\
\text { fordista/moderno, teoria do } \\
\text { autor-rede }\end{array}$ & $\begin{array}{l}\text { De industrialismo/ } \\
\text { modernidade a } \\
\text { pós- } \\
\text { industrialismo/ } \\
\text { pós-modernidade }\end{array}$ & $\begin{array}{l}\text { Foucault, } \\
\text { Garfinkel }\end{array}$ \\
\hline Justiça & Participação & $\begin{array}{c}\text { Ética de negócios, moralidade } \\
\text { e OB, democracia industrial, } \\
\text { teoria participativa, teoria } \\
\text { crítica }\end{array}$ & $\begin{array}{l}\text { De democracia } \\
\text { repressiva a } \\
\text { democracia } \\
\text { participativa }\end{array}$ & $\begin{array}{l}\text { Adorno, } \\
\text { Horkheimer, } \\
\text { Marcurse, } \\
\text { Habermas } \\
\end{array}$ \\
\hline
\end{tabular}

Fonte: Adaptado de Reed, 1999.

Segundo Waldo (1948), autores como Taylor, Fayol e Brech afirmam que leis científicas de administração seriam utilizadas para reger a sociedade e as unidades

Revista ENIAC Pesquisa, Guarulhos (SP), V.7, n.1, jan.- jun. 2018. 
organizacionais, não incluindo valores e emoções humanas. Os homens seriam matériasprima, que poderiam transformar-se em seres bem comportados, produtivos e que não interferissem nos planos das classes dominantes (REED, 1999).

A problemática da ordem baseava-se na racionalização do desempenho, eficiência, controle operacional, formalismo excessivo e regras. As decisões seriam tomadas racionalmente, por meio do conhecimento qualificado e da legalidade e a lógica garantiria o progresso material, social e a ordem política da sociedade (REED, 1999).

Em seguida, entra em cena a narrativa da Integração, que buscava redescobrir a comunidade. Reed (1999) sustenta que o racionalismo exacerbado fez com que surgisse uma necessidade de base teórica alternativa ao poder e autoridade, sendo que essa base deveria possuir um sentimento de comunidade entre os membros, já que, conforme Bendix (1974), sem colaboração espontânea ou intencional a autoridade não seria eficaz.

Sendo assim, surge a escola da relações humanas, teoria da contingência, o funcionalismo estrutural, entre outras teorias, que buscavam entender as realidades sociais, a integração, a cooperação e até mesmo os conflitos. A organização deveria buscar o companheirismo, ao mesmo tempo que provesse bens e serviços (WOLIN, 1961).

Uma narrativa que leva em desvantagem a sociedade, o serviço público e as preocupações sociais é a de mercado, que surge protegendo a racionalidade econômica, a iniciativa privada e a expansão do mercado (BENDIX, 1974). Nessa visão, o determinismo ambiental está presente, e os mercados conseguiriam ajustar preço e custo, entrando em equilíbrio, sem a necessidade de uma "organização" (REED, 1999).

As organizações seriam responsáveis por reduzir o custo das transações, pois diminuiriam a desconfiança entre os agentes econômicos que trocam seus produtos e serviços constantemente, aumentando a eficiência e a alocação de recursos dentro do sistema de mercado (REED, 1999). Para o autor, pela liberdade e igualdade entre agentes econômicos que negociariam e monitorariam contratos em acordos de mercado, surgiria a necessidade das organizações.

Para Williamson (1990), uma das teorias da narrativa de mercado é lidar com as limitações institucionais em que as transações econômicas ocorrem, de forma a estudar as estruturas das organizações e os elos com funções organizacionais. Além desta, na análise do custo de transação e na ecologia populacional as empresas buscariam a eficiência e sobrevivência, que estariam além do controle humano. Aquela teoria buscaria ajustes para

Revista ENIAC Pesquisa, Guarulhos (SP), V.7, n.1, jan.- jun. 2018. 
maximizar a eficiência em suas transações, já esta teoria focaria nas pressões competitivas entre agentes (REED, 1999).

A metanarrativa seguinte é o Poder, em que a problemática central é a dominação. A organização seria o local em que interesses e o embate de valores estariam presentes e em que se lutaria pelo poder, para que assim se buscasse a eficiência e eficácia e a sobrevivência a longo prazo seria garantida. Clegg (1989) e Wrong (1978) definem, segundo os escritos de Weber, que o poder é um recurso que está presente de forma distinta entre os agentes, e que se utilizado com habilidade estratégica produziria relações hierárquicas de autonomia e dependência.

O poder, segundo Lukes (1974), teria “múltiplas facetas", e poderia ser dividido entre o "episódico", que centraria em confitos de interesse entre autores identificáveis, o "manipulativo", que seriam os grupos que manipulam o processo de tomada de decisão a seu favor, e o "hegemônico", que seriam as estruturas ideológicas e sociais existentes que moldariam os interesses (REED, 1999).

Seguindo as metanarrativas, encontra-se a do Conhecimento, que prega que um conjunto de técnicas advindo do conhecimento seria utilizado para a construção de regimes disciplinares, que concederia poder à organização (CLEGG, 1994). Qualquer indivíduo com treinamento e habilidade poderia dominar conhecimentos que seriam utilizados para gerir a organização (BLACKLER, 1993).

A organização teria conhecimentos sociais, técnicos e de habilidades que fariam nascer e reproduzir os relacionamentos sociais (LAW, 1994). A cultura de valor local, o poder, as regras, entre outros, estariam sintetizados dentro das organizações (CLEGG, 1994).

A última metanarrativa, a Justiça, aborda a problemática da participação, e sustenta a necessidade que o local e o global sejam reconectados, assim como as práticas e processso da organização com a racionalidade e estrutura institucional, além da reconexão da ordem e do controle e poder (REED, 1999). Reed (1994) postula que esta narrativa baseada na democracia procura reunir os discursos e práticas locais com ordens de poder e de controle organizacional, que possui "racionalidade social e dinâmica históricas específicas".

Não obstante as contribuições de Reed para os estudos organizacionais tenha sido de grande importância, é importante ressaltar que pesquisas de natureza epistêmica, portanto, de profundidade ainda maior no campo da produção científica, já vêm sendo

Revista ENIAC Pesquisa, Guarulhos (SP), V.7, n.1, jan.- jun. 2018. 
realizadas desde a década de 1960. Com efeito, o trabalho intitulado "Sociological paradigms and organizational analysis: elements of the sociology of corporate life", de Burrel e Morgan (1979) tornou-se um clássico do assunto e ainda tem despertado muitos debates (DEETZ, 1996).

Apesar de qualquer tentativa de síntese crítica sobre as contribuições de Burrel e Morgan (1979) seja arriscada, algumas considerações são necessárias. De fato, é importante ressaltar para que o modelo proposto, ao partir da tese da incomensurabilidade dos paradigmas, limitando o campo das ciências humanas e sociais aos quatro paradigmas de conhecimento, estabelecidos a partir da matriz sujeito-objeto/revolução-regulação, proporcionou não apenas novas possibilidades de pesquisas, mas também verdadeiras guerras paradigmáticas entre os teóricos do campo (JACKSON; CARTER, 1993). Não obstante os prejuízos e ganhos relativos às disputas decorrentes, no caso dos estudos organizacionais, a limitação dos paradigmas também apontou para a necessidade de compreender zonas de intersecção, de ampliação e revisão dos paradigmas aceitos e da tese da incomensurabilidade.

É a partir desse contexto que Paula (2016) desenvolve o Círculo das Matrizes Epistemológicas, com o objetivo de apresentar uma alternativa às teses de Burrel e Morgan (1979), uma vez que estes, inspirados em Thomas Kuhn (1969), inseriram a teoria da incomensurabilidade kuhniana no campo das ciências sociais, transportando e correlacionando reflexões e teses do campo das ciências naturais para o campo das ciências humanas e sociais.

De acordo com o modelo de Paula (2016), a geração do conhecimento é dinamizada por três interesses cognitivos distintos, orientados por questões axiológicas e ideológicas quais sejam: o técnico, que se orienta pelo interesse satisfatório das ciências naturais; o prático, na qual possibilita a compreensão mútua a partir da interação desse conhecimento e; o emancipatório, cujo interesse é reflexivo e crítico, possibilitando o resgate filosófico no processo epistêmico. Decorrente do interesse e das questões de ordem ideológica e axiológicas, seria possível então compreender as ciências como empíricoanalíticas, hermenêuticas e as ciências críticas (PAULA, 2016). A Figura 1 explicita as áreas do conhecimento propostas por Paula.

Revista ENIAC Pesquisa, Guarulhos (SP), V.7, n.1, jan.- jun. 2018. 
Figura 1: Círculo de matrizes epistêmicas, abordagens sociológicas, teorias e metodologias.

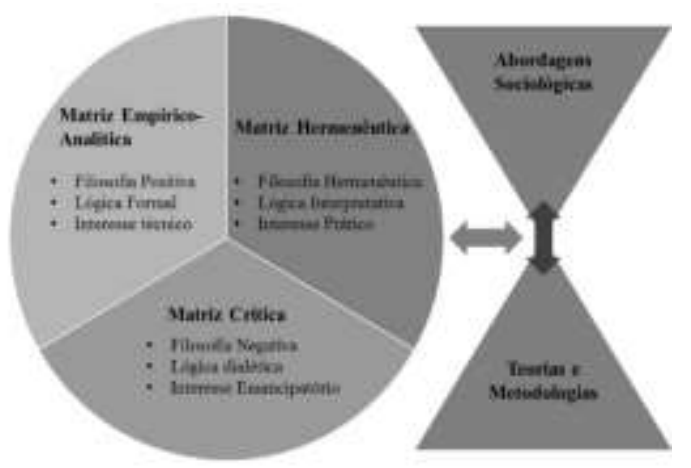

Fonte: Adaptado de Paula, 2016.

A Figura 1 evidencia as três bases epistemológicas e seus correspondetes sistemas de lógica e interesse. Conforme pode ser observado, a matriz empírico-analítica englobaria a preferância pelo interesse técnico, o uso da lógica formal e o alinhamento com a filosofia positiva. Com efeito, nesta dimensão epistémica, o movimento positivista seria marcado pelo caráter empírico e pela formalidade, consubstanciando as explicações causais de orientação axiologicamente neutra, cuja finalidade seria o interesse técnico e a instrumentalidade. A matriz hermenêutica, por sua vez, seria delineada pelo uso da lógica interpretativista, pela filosofia hermenêutica, e pelo interesse prático, possuindo como caracteristica a mediação do sujeito que interpreta a realidade, portanto, que construi e reconstrui sentidos e significados, e, assim, orientações para a ação social. Já a matriz crítica seria caracterizada pela filosofia negativa, buscando assim atingir o conteúdo das proposições pautando-se nas multiplnas e complexas contradições e, assim, nas possibilidades de mudança; outra característica desta matriz seria a orientação pelo emancipação, cuja implicação abarcaria a atuação nas questões políticas, indo além das faces utópicas.

Não obstante o esquema explicativo acima, Paula (2016) explicita que a separação dos conhecimentos, e especificamente das matrizes epistêmicas, deve ser relativizada, uma vez que o pensamento no campo das ciências sociais tem um sentido transdisciplinar, gerando assim pontos de interseções entres as matrizes epistêmicas. Assim, é preciso observar que:

O interesse emancipatório sozinho torna-se crítica pela crítica, visto que depende dos interesses prático e técnico para se concretizar em ações; o interesse prático isolado tende a se transformar em pura compreensão e

Revista ENIAC Pesquisa, Guarulhos (SP), V.7, n.1, jan.- jun. 2018. 
descrição, uma vez que precisa dos interesses técnicos e emancipatórios para ser capaz de interferir na realidade; e o interesse técnico apenas, converte-se em instrumentalismo, pois é necessário também contemplar as necessidades sociais de compreensão e emancipação (PAULA, 2016, p. 37).

Nesse contexto, a Figura 2 apresenta as interseções geradas pelas matrizes epistêmicas, deixando claro que é um desenvolvimento em vista a superar a imcompletude cognitiva, uma vez que as metodologias e teorias perspassam as matrizes epistêmicas gerando recontruções epistêmicas (PAULA, 2016).

Figura 2: Interconexões geradas pelas abordagens sociológicas.

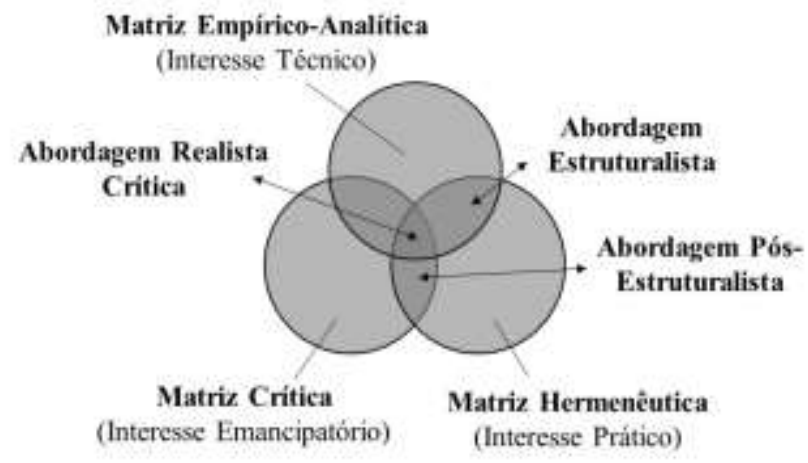

Fonte: Adaptado de Paula, 2016.

É importante detacar que as matrizes epistémicas identificam-se com as chamadas abordagens sociológicas puras, descritas como abordagens funcionalista, interpretativista e humanista, estas, estão correspondendo sequencialmente à matriz empírico-analítica, à hermenêutica e à crítica.ser identificada.

Além das abordagens sociológicas puras, a Figura 2 indica que existem pontos de transição entre as abordagens, sendo esses pontos de transição representados pelas abordagens sociológicas híbridas, ou seja, abordagens que não se limitam às regiões fronteiristas do conhecimento, e sim, transitam entre os conhecientos puros, como é o caso da abordagem estruturalista que transitaria entre as matrizes empírico-analítica e hermenêutica, da pós-estruturalista que permeiaria a matriz hermenêutica e crítica, e por fim, a realista crítica que transitaria pela matriz empírico-analítica, hermenêutica e crítica (PAULA, 2016). Portanto, conforme a autora, trata-se de reconstruções epistêmicas, não tratando-se de rupturas paradigmáticas, uma vez que essa reconstrução busca a superação da imcompletude cognitiva, além da criação de abordagens sociológicas que fomentem a conciliação dos interesses cognitivos pautados nas matrizes epistêmicas.

Revista ENIAC Pesquisa, Guarulhos (SP), V.7, n.1, jan.- jun. 2018. 


\section{TAXONOMIA E ESTRATÉGIA METODOLÓGICAS}

Este estudo pode ser entendido como qualitativo, uma vez que busca compreender e descrever o fenomeno, não se preocupando com as relações explicaticas sintetizadas em relações numéricas. Quanto ao objetivo, trata-se de uma pesquisa exploratória, considerando que introduz aos estudos organizacionais de orientação epistémica um campo inesplorado, além de apontar carateristicas fundamentais a repeito das pesquisa relacionadas ao agronegócio (GIL, 2002; GERHARDT; SILVEIRA 2009).

Quanto ao procedimento técnico utilizado para coleta de dados, a pesquisa assume forma de estudo bibliográfico e documental. De fato, a pesquisa foi desenvolvida com base em material já elaborado, constituído de teses e dissertações de Pós-graduação em Administração. De acordo com Gil (2002), essas fontes são importantes para a pesquisa, já que são constituídas de relatórios de investigações científicas originais ou resultantes de revisões bibliográficas.

Com base nessa metodologia, a primeira tentativa de encontrar dissertações e teses em administração com linha de pesquisa em agronegócios, por meio do site periódico Capes, demonstrara dados encontrados inconsistentes. Foram encontrados anais, apresentações de congressos, entre outros, e, por esse motivo, não foram utilizados. Com efeito, Gil (2002) ressalta que os pesquisadores devem assegurar as condições em que os dados foram obtidos e analisar as informações em profundidade para descobrir possíveis incoerências.

Em seguida, uma busca de todos os programas de pós-graduação no país foi feita por meio da plataforma Sucupira/Capes. Os programas buscados foram aqueles cuja área de avaliação fosse administração, ciências contábeis e turismo (área 027), a área básica fosse administração e que estivessem em funcionamento, resultando em um total de 125 . Desse total, foram retirados os programas voltados para ciências contábeis, gestão do esporte, gestão de políticas e organizações públicas.

Posteriormente foi verificado em todas os programas listados quais possuíam linhas de pesquisa em agronegócios ou agroindústria (Tabela 1), excluindo programas de sustentabilidade e desenvolvimento regional que não possuíam essa linha, resultando em 8 programas. Desse total, 3 programas são novos e, por isso, ainda não possuem dissertações ou teses apresentadas.

Revista ENIAC Pesquisa, Guarulhos (SP), V.7, n.1, jan.- jun. 2018. 
Tabela 1: Programas com linha de pesquisa em agronegócios ou agroindústria.

\begin{tabular}{|c|c|c|}
\hline Universidades & Programas & $\begin{array}{l}\text { Ano de } \\
\text { Fundação }\end{array}$ \\
\hline $\begin{array}{l}\text { Fundação Universidade Federal de Mato Grosso } \\
\text { do Sul }\end{array}$ & Administração & 2010 \\
\hline Universidade Federal Rural de Pernambuco & Administração & 2012 \\
\hline Universidade do Oeste de Santa Catarina & Administração & 2013 \\
\hline Universidade Estadual do Oeste do Paraná & Administração & 2013 \\
\hline Universidade Estadual do Oeste do Paraná & Gestão e desenvolvimento regional & 2013 \\
\hline Universidade Federal de Pelotas & $\begin{array}{c}\text { Desenvolvimento Territorial e Sistemas } \\
\text { Agroindustriais }\end{array}$ & 2013 \\
\hline $\begin{array}{c}\text { Universidade de São Paulo/Escola Sup. De } \\
\text { Agricultura Luiz de Queiroz }\end{array}$ & Administração & 2014 \\
\hline $\begin{array}{c}\text { Universidade Est. Paulista Júlio De Mesquita } \\
\text { Filho/Jaboticabal }\end{array}$ & Administração & 2014 \\
\hline
\end{tabular}

Fonte: Elaborado pelos autores, 2017.

Logo, buscou-se no repositório institucional das bibliotecas dessas instituições as dissertações e teses disponibilizadas desses programas, resultando em um total de 184 pesquisas, sendo estas analisadas a seguir. A análise foi feita com base nos estudos de Reed (1999) e de Paula (2016). Também foram observadas as características metodológicas dos estudos, conspirando: natureza da pesquisa, permeando as pesquisas qualitativa, quantitativa e mista; em relação à finalidade (exploratória e descritiva); ainda assim, a estratégia de pesquisa, o estudo de caso. Além disso foi observado a temática das dissertações a partir de suas palavras-chave.

Em relação à análise de dados segundo as perspectivas teóricas e epistêmicas, foi utilizada a técnica de análise de conteúdo, em que se busca por meio de procedimentos sistemáticos e objetivos descrever o conteúdo daquilo que se investiga. Segundo Bardin (2009), essa técnica consiste na fase de pré-análise, de exploração do material e de tratamento dos resultados, inferências e interpretação. Na pré-análise o material foi organizado, de modo a torná-lo operacional e foi feito o plano de análise (BARDIN, 2009).

$\mathrm{Na}$ fase de exploração do material, de acordo com Bardin (2009), a aplicação sistemática das decisões tomadas foi implementada, com codificação ou enumeração em função das categorizações formuladas primeiramente. Em seguida, foi realizado o tratamento dos resultados, inferência e interpretação. Nessa fase, conforme menciona Bardina (2009), um quadro de resultados que resume e disponibiliza as informações

Revista ENIAC Pesquisa, Guarulhos (SP), V.7, n.1, jan.- jun. 2018. 
analisadas de forma reflexiva e crítica foi elaborado, para que os analistas pudessem propor inferências e interpretações a propósito do resultado que se busca.

\section{RESULTADOS E DISCUSSÃO}

Neste tópico são apresentados e discutidos os resultados da pesquisa, divididos nos seguintes subtópicos: teorização das pesquisas no agronegócio, bases epistêmicas, metodologia e temática.

\subsection{TEORIZAÇÃO DAS PESQUISAS NO AGRONEGÓCIO}

Conforme apresentado por Waiandt e Fischer (2013), a pesquisa "Teorização Organizacional: um Campo Historicamente Contestado" de Michael Reed (1999) é um dos artigos mais utilizados para o ensino dos Estudos Organizacionais, estando presente em grande parte dos cursos de pós-graduação em administração.

No panorama geral dos programas com linha de pesquisa em agronegócio ou agroindústria, as dissertações foram categorizadas segundo o modelo de metanarrativas de Reed (1999). Assim, foram identificadas 127 dissertações voltadas à análise interpretativa Mercado, em que os trabalhos abordam em sua maioria questões de eficiência mercadológica, social e econômica, economia institucional, custos de transação e estudos focados na atuação da organização com dependência de recursos, como por exemplo dissertações objetivando estudos: de análise SWOT (análise de questões mercadológicas visando as oportunidades, ameaças, forças e fraquezas) em empresas da indústria metalmecânica em busca de competitividade; de análise de quais vantagens competitivas de cafés especiais produzidos de forma orgânica, para uma cadeia produtiva do agronegócio; e também, um estudo universitário fomentando melhorias no cultivo de cana-de-açúcar.

De acordo com Reed (1999), todas as teorias cuja problemática central fosse a liberdade defendem a expansão do mercado, de uma economia mais racional e da iniciativa privada, permanecendo negligentes às questões como comunidade, preocupações da sociedade e serviços prestados pelo Estado, o que pode ser visto nas 126 dissertações enquadradas como de Mercado.

Ainda assim, em relação ao modelo de Reed (1999), foram identificadas 48 dissertações que possuem uma abordagem de análise interpretativa marcada pela Integração, em que foi possível categorizá-las por tratarem de questões relacionadas com o capitalismo do bem-estar, especificamente por expressões que remetem o uso da escola

Revista ENIAC Pesquisa, Guarulhos (SP), V.7, n.1, jan.- jun. 2018. 
de relações humanas (teoria de sistemas e contingências), o funcionalismo, além de questões voltadas a explorar mudanças sociais a partir de culturas corporativas, nas quais podemos apresentar alguns assuntos tratados, como: o caso da dissertação que tem como objetivo a análise de quem qual medida o Programa Nacional de Produção e Uso do Biodiesel (PNPB) influencia a inserção da agricultura familiar no espaço geográfico da pesquisa; e também, um estudo que tem a finalidade de analisar o Programa Bolsa Família, para com isso, apresentar os impactos nas variáveis sociais, como a pobreza e a desigualdade de renda.

Outra abordagem analítica interpretativa identificada foi a de Conhecimento, que contou com 4 dissertações, nas quais remetem a ideia de proteção do conhecimento, além de mecanismos de conhecimento empresarial tácito visando um certo tipo de poder em relação aos subordinados. Na teoria foi possível corroborar os resultados em que Clegg (1994), Blacker (1993) e Law (1994) explicitaram que o conhecimento, que poderia ser dominado por qualquer pessoa dentro da organização, gera poder que seria utilizado para que regimes disciplinares fossem construídos e para que relacionamentos sociais fossem estabelecidos. Os estudos caracterizados a partir dessa metanarrativa objetivam estudos sobre: análise do uso da modalidade de educação à distância nos cursos de Agronegócio; a participação discente na produção científica em programas brasileiros de pós-graduação em administração; a contribuição da implantação de uma unidade acadêmica para os processos de aprendizagem e inovação em um arranjo produtivo; a análise de como um grupo de lavanderias estão desenvolvendo a aprendizagem organizacional frente às exigências de adequação ambiental.

Referente a metanarrativa Poder, foram identificadas 3 dissertações com essa característica, nas quais foram possíveis identificar um viés teórico e metodológico voltado a dominação de indivíduos por técnicas hierárquicas estratégicas visando uma manipulação de processos decisórios, assim como afirmam os autores Clegg (1989) e Wrong (1978). Nesse contexto, as dissertações foram categorizadas a partir da metanarrativa Poder por trazerem discussões: acerca do modo de produção dominante, o capitalismo, apresentando críticas e alternativas à superação dessa dominação hegemônica; sobre a identificação de processos de fragmentação e hierarquização no trabalho de docentes em um programa de $\mathrm{EaD}$ de ensino superior voltado ao Agronegócio; como também, resultados explicitando um conjunto de regras e normas são influências diretas na geração de satisfação ou não na permanência de pessoas em instituições religiosas.

Revista ENIAC Pesquisa, Guarulhos (SP), V.7, n.1, jan.- jun. 2018. 
No contexto da Racionalidade, outra abordagem analítica interpretativa, foi identificado uma dissertação com esse viés, que explicita mecanismos com uma formalidade excessiva e alto controle operacional visando uma eficiência produtiva, na qual a dissertação identificada por essa metanarrativa analisou o uso da incorporação de uma modelagem através de técnicas de gestão por competências em uma empresa de Call Center. Mecanismos estes que são citados em trabalhos como de Frug (1984) e Presthus (1975) que asseguram que haveria funções técnicas objetivas para que a ordem social funcionasse de maneira efetiva e eficiente e que fosse fundamentada em uma autoridade racional-legal.

Em relação a Justiça, foi identificado uma dissertação com esse viés, e foi possível caracterizá-la, pois, no referencial teórico do trabalho a autora utilizou-se da dialética para apresentar as teorias apresentadas, além de que em seus resultados houveram críticas em relação ao capitalismo como uma forma hegemônica que tem seus defeitos e precisa ser empreendida formas alternativas ao sistema hegemônico, em relação social e econômica, especificamente, a dissertação enquadrada nessa metanarrativa verifica se o campesionato que se reproduz atualmente o faz de maneira autônoma, partindo da discussão da luta camponesa pela terra e vida na terra. Assim como explicita Cable (1994), no trabalho foi possível encontrar o contexto sociopolítico que está em mudança e a tentativa de se pensar no relacionamento do homem e da comunidade que busca esse programa de identidade política.

Sumarizando os dados obtidos com a pesquisa, em um universo de 184 dissertações, foram identificadas $68,48 \%$ das dissertações possuem um viés voltado a metanarrativa Mercado, 26,09\% dos trabalhos foram identificados possuindo um viés de Integração, $2,17 \%$ foi a percentagem de trabalhos que detinham um viés de Conhecimento e na mesma proporção Poder, e, por fim, 0,54\% das dissertações possuíam um viés de Racionalidade, e no mesmo patamar, Justiça.

Dentre as 184 teses e dissertações apresentadas em cada programa e disponibilizadas pelo repositório institucional das universidades investigadas, 116 são do programa da Universidade Federal Rural de Pernambuco-UFRP, 38 são da Universidade Federal do Mato Grosso do Sul-UFMS, 14 da Universidade do Oeste de Santa CatarinaUNOESC e 16 da Universidade Estadual do Oeste do Paraná-UNOESTE (11 no programa de Gestão e Desenvolvimento e 5 no de Administração).

Revista ENIAC Pesquisa, Guarulhos (SP), V.7, n.1, jan.- jun. 2018. 
Os programas da Universidade de São Paulo/Escola Superior de Agricultura Luiz de Queiroz, da Universidade Est. Paulista Júlio De Mesquita Filho/Jaboticabal e da Universidade Federal de Pelotas são programas novos, e, por isso, não possuem teses e dissertações publicadas. Em seguida serão apresentados os dados específicos de cada programa de mestrado (Tabela 2):

Tabela 2: Metanarrativas identificadas em relação aos programas de mestrado.

\begin{tabular}{|c|c|c|c|c|}
\cline { 2 - 5 } \multicolumn{1}{c|}{} & UFMS & UFRP & UNOESC & UNOESTE \\
\hline Racionalidade & & 1 & & \\
\hline Integração & 12 & 29 & 4 & 3 \\
\hline Mercado & 21 & 82 & 9 & 13 \\
\hline Poder & 3 & & 1 & \\
\hline Conhecimento & 2 & 2 & & \\
\hline Justiça & & 1 & & \\
\hline
\end{tabular}

Fonte: Elaborado pelos autores, 2017.

Nesse contexto fica explícito que a metanarrativa que mais foi identificada foi a relacionada ao Mercado, indicando que os programas voltados ao agronegócio ou agroindústria, possuem um caráter voltado a transações econômica e busca pela eficiência econômica (REED, 1999; WILLIAMSON, 1990; BENDIX, 1974). Na sequência tem-se as dissertações voltadas a Integração, possuindo um caráter de análise a partir das escolas de relações humanas e também pela compreensão da realidade social que indivíduos ou organizações vivem (BENDIX, 1974; WOLIN, 1961).

\subsection{BASES EPISTÊMICAS}

Além da análise feita a partir do estudo de Reed (1999), foram identificadas também em quais bases epistêmicas estavam apoiadas as dissertações com base nos estudos de Paula (2016). Assim, foi possível identificar 174 dissertações em relação a matriz empíricoanalítica, que de uma maneira específica conta com a junção das metanarrativas Racionalidade, Integração e Mercado, pois apresentam um caráter de lógica formal e interesse nos mecanismos técnicos visando um objetivo organizacional, características presentes no movimento positivista.

Foram identificadas também 8 dissertações relacionadas a matriz hermenêutica, que conta com as metanarrativas voltadas ao Poder e Conhecimento, e que de uma maneira ampla, foi possível identificar interesse nas práxis, além do uso da lógica interpretativa. Ainda assim, foi identificada uma dissertação que tinha relação com a matriz crítica, que é

Revista ENIAC Pesquisa, Guarulhos (SP), V.7, n.1, jan.- jun. 2018. 
caracterizada pela metanarrativa Justiça, e foi possível identificar no trabalho interesses emancipatórios e uso da dialética.

Não obstante, a análise do círculo de matrizes epistêmicas proposta por Paula (2016) foi caracterizada relacionando as metanarrativas propostas por Reed (1999), objetivando a identificação das dissertações a partir da teorização das pesquisas no agronegócio.

\subsection{METODOLOGIA}

No contexto metodológico, foi possível identificar entre as 184 dissertações analisadas, 102 trabalhos com abordagem qualitativa. Essa abordagem é caracterizada por expor o objeto de estudo a partir de fonte direta de coleta de dados, ao passo que o pesquisador é o instrumento chave dessa abordagem (SILVA; MENEZES, 2005). Ainda assim, Richardson (2008) complementa que a abordagem qualitativa tem o objetivo de uma tentativa de compreensão em detalhes das características do objeto estudado.

Outra abordagem identificada foi a quantitativa, utilizada em 33 dissertações. A pesquisa quantitativa tem por objetivo uma investigação por meio de planejamentos, a partir de variáveis definidas, a quantificação e integração dos dados coletados (GODOY, 1995). Portanto, essa abordagem desenvolve-se a partir da precisão e evita quaisquer distorções de dados, garantindo o controle da subjetividade dos resultados apresentados pelo pesquisador (MARTINS, 2004). Ainda no contexto das abordagens metodológicas, 49 dissertações possuem uma abordagem mista, ou seja, abordagem que integra tanto a pesquisa qualitativa, quanto a quantitativa. Creswell (2010) define o método misto a partir da investigação que possui a combinação ou associação das formas qualitativas e quantitativas.

Quanto à finalidade de pesquisa, foram citadas as pesquisas exploratórias e descritivas. Embora algumas dissertações possuam ambos tipos de pesquisa, afim de quantifica-las foram separadas em variáveis diferentes, mas ressalta-se que diversas dissertações se caracterizam tanto com o tipo de pesquisa exploratória, quanto a descritiva. Assim, 143 dissertações ressaltaram utilizar o tipo de pesquisa exploratório. Esse tipo de pesquisa é fomentado pelo objetivo de desenvolver questões de pesquisa ou hipóteses para futuras pesquisas (YIN, 2010). Cooper e Schindler (2011) corroboram que essa característica de pesquisa tem o objetivo de examinar de uma maneira minuciosa os objetivos ou variáveis definidas pelo pesquisador.

Revista ENIAC Pesquisa, Guarulhos (SP), V.7, n.1, jan.- jun. 2018. 
Outro tipo de pesquisa encontrado foi o descritivo, em que 57 dissertações utilizaram essa ferramenta metodológica. A pesquisa descritiva tem o objetivo de apresentar e descrever os dados coletados a partir da finalidade da pesquisa (ROESCH, 2009). Ainda assim, essa pesquisa tem o objetivo de descrever determinados fenômenos (COLLIS; HUSSEY, 2005).

No que diz respeito ao procedimento e estratégia de aproximação como o objeto estudado, das 186 dissertações analisadas, 136 pesquisas utilizaram o estudo de caso, sendo que as demais dissertações utilizaram dados secundários e fontes documentais para as suas pesquisas. Segundo Yin (2010), a estratégia estudo de caso é adaptável em diversas situações e objetiva a geração de conhecimentos novos em diversas áreas da ciência, permitindo a investigação de eventos cotidianos. Vergara (2009) completa, que o estudo de caso fomenta a discussão de resultados de um abeto de estudo e pode ou não ser realizada uma pesquisa em campo. Nesse contexto, foi observado estudos relacionados: aos agricultores, sejam eles familiares ou não; instituições de ensino público; empresas privadas; e políticas nacionais.

Sumarizando os procedimentos e técnicas utilizadas nas dissertações estudadas, segue a Tabela 3, ainda que, em relação as abordagens analíticas, as dissertações poderiam utilizar mais de uma abordagem no mesmo trabalho.

Tabela 3: Métodos e técnicas de pesquisa.

\begin{tabular}{|c|c|c|c|}
\hline Abordagem & Qualitativa & Quantitativa & Mista \\
\hline Quantidade & 102 & 33 & 49 \\
\hline
\end{tabular}

\begin{tabular}{|c|c|c|c|}
\hline $\begin{array}{c}\text { Abordagem } \\
\text { Analítica }\end{array}$ & Exploratória & Descritiva & $\begin{array}{c}\text { Estudo } \\
\text { de Caso }\end{array}$ \\
\hline Quantidade & 143 & 57 & 136 \\
\hline
\end{tabular}

Fonte: Elaborado pelos autores, 2017.

\subsection{TEMÁTICA}

Analisando as temáticas de maior recorrência dentre as dissertações por meio das palavras-chave, foi possível identificar o vocábulo "desenvolvimento" como o mais citado, com 28 citações, podendo ser divido em desenvolvimento sustentável, local, rural, regional, econômico. O estudo de Abbade (2014) mostra que o desenvolvimento de atividade e desempenho do setor de agronegócios brasileiro está intimamente ligado ao desenvolvimento econômico do país, e assim, há muitos estudos relacionados à temática.

Em seguida, formas de "gestão" são as mais estudadas, contando com 19 aparições, dentre elas, gestão de pessoas e gestão ambiental. Para aumentar o nível de

Revista ENIAC Pesquisa, Guarulhos (SP), V.7, n.1, jan.- jun. 2018. 
competitividade, os administradores de organizações relacionadas ao agronegócio buscam eficiência na administração e, por isso, vem ampliando seus conhecimentos na gestão (CALLADO; CALLADO, 2009). Sendo assim, o autor corrobora com o fato de que muitas pesquisas sejam desenvolvidas com o tema "gestão".

Não obstante, podem ser encontradas "políticas públicas" e a "agricultura familiar" com 17 citações, com 16 aparições tem-se o vocábulo "sustentabilidade", com 12, turismo, e com 11 surge o "agronegócio". Além do estudo de "estratégias" com 10 dissertações e os "Arranjos Produtivos Locais", com 9.

\section{CONSIDERAÇÕES FINAIS}

O objetivo deste estudo foi identificar o enfoque teórico-metodológico e epistemológico empregado nas dissertações e teses desenvolvidas entre 2005 e 2015 em Programas de Pós-graduação em Administração com linhas de pesquisa em agronegócio no Brasil. Buscou-se, espeficicamente, caracterizar as teorias e metodologias utilizadas na elaboração dessas pesquisas.

Em relação a teorização das pesquisas no agronegócio identificou-se que a maior parte das dissertações (126) estão voltadas à análise interpretativa Mercado, defendendo um mercado mais expansivo, distante da racionalidade econômica presente na iniciativa privada e suas consequências negativas à comunidades e sociedade em geral, incluindo ações regidas pelo Estado. Foram identificadas 48 dissertações com enfoque na abordagem de análise interpretativa com destaque na Integração, dando voz a temas como capitalismo do bem-estar e escola de relações humanas. A análise interpretativa com enfoque no Conhecimento possui 4 dissertações voltadas a própria concepção da proteção do conhecimento. Paralelamente, outras 4 dissertações têm enfoque na metanarrativa Poder, conjecturando a impetuosa ideia da dominação de indivíduos por meio de técnicas de hierarquia para a influência e controle em processos de decisão uma vez democráticos. Identificou-se uma dissertação para a metanarrativa Racionalidade, com um explítico viés analítico sobre a formalização de elevados mecanismos controle operacional, e outra em relação a Justiça, composta por teoria dialética e críticas ao capitalismo. Evidencia-se, portanto, maior enfoque para a metanarrativa Mercado $(68,48 \%)$ e, em segundo lugar, para o viés Ingeração $(26,09 \%)$.

Destaca-se que a maior parte das dissertações são programa da Universidade Federal Rural de Pernambuco-UFRP (116) e Universidade Federal do Mato Grosso do Sul-

Revista ENIAC Pesquisa, Guarulhos (SP), V.7, n.1, jan.- jun. 2018. 
UFMS (38), possivelmente por questões do tempo de atuação das linhas teóricas dos programas de mestrado. O número elevado de enfoque para o Mercado possivelmente ocorrem por causa da abordagem dos programas de mestrados, pois estão ligados a linha teórica de agronegócios ou agroindústria.

Em relação às bases epistêmicas, verificou-se que a maior parte das dissertações estão relacionadas a matriz empírico-analítica (174), pois, destaca-se a junção das metanarrativas Racionalidade, Integração e Mercado, pois, conforme Paula (2016), existe naturalmente a criação de abordagens sociológicas capazes de criar a conciliação da coletividade e seus próprios interesses. A matriz hermenêutica contou com 8 dissertações com metanarrativas voltadas ao Poder e Conhecimento.

Quanto à metodologia, verificou-se um número elevado de trabalho com abordagem qualitativa (102), pois, a pesquisa qualitativa é facilmente aplicada em pesquisas que buscam um detalhamento do seu objeto de estudo. Além disso, verificou-se um baixo número de estudos com abordagem quantitativa (33), possivelmente por considerar que esta abordagem envolve cálculos matemáticos e estatístico, a partir da quantificação dos dados coletados. A abordagem mista foi utilizada (49), reforçando a integração de duas abordagens fortemente distinstas. É importante destacar que a maior parte das dissertações ressaltaram utilizar o tipo de pesquisa exploratório (143), facilmente justificado pelo forte desígnio de desenvolver abordagens e questões de pesquisas ou hipóteses que extrapolem fronteiras do conhecimento e contribuam para novas pesquisas. Identificou-se uma elevada utilização do estudo de caso (136), refletindo no forte interesse dos pesquisadores em conhecer o objeto de estudo de maneira mais profunda e sistemática.

Não obstante, a presença de muitas dissertações que pesquisam a temática do desenvolvimento e que possuem a metanarrativa de mercado é condizente com o atual cenário do agronegócio do país, área vista como um dos vetores do crescimento econômico do país. Segundo Abbade (2014), o crescimento econômico acentuado do Brasil nas últimas décadas se deve em grande parte ao desenvolvimento das atividades agrícolas. A abertura dos novos cursos de Pós-Graduação em Administração com linhas de pesquisa em agronegócio corrobora com a tese do avanço dessa área de pesquisa no Brasil.

A recenticidade dos Programas de Pós-Graduação em Administração com linha de pesquisa em Agronegócio explica as poucas dissertações disponibilizadas. Para futuras pesquisas seria interessante a investigação das linhas de Agronegócio pertencentes a outras áreas de pesquisa classificadas pela plataforma Sucupira-Capes, como a área

Revista ENIAC Pesquisa, Guarulhos (SP), V.7, n.1, jan.- jun. 2018. 
Interdisciplinar e a de Agronomia, onde poderiam ser encontradas mais dissertações e teses visando o agronegócio.

\section{REFERÊNCIAS}

ABBADE, E. B. O papel do agronegócio brasileiro no seu desenvolvimento econômico. Gestão da Produção, Operações e Sistemas, Bauru, Ano 9, nº 3, p. 149-158, 2014.

ARGYRIS, C. Integrating the individual and the organization. New York: Wiley, 1964.

BARDIN, L. Análise de conteúdo. Lisboa, Edições 70, 2009.

BENDIX, R. Work and authority in industry. California: University of California Press, 1974.

BLACKLER, F. Knowledge and the theory of organizations: organizations as activity systems and the reframing of management. Journal of Management Studies, 30: 86384, 1993.

BLAU, P., SCOTT, W.R. Formal organizations: a comparative approach. Londres: Routledge and Kegan Paul, 1963.

BRASIL. Ministério da Agricultura, 2015. Disponível em: <http://www.agricultura.gov.br/comunicacao/noticias/2015/06/agronegocio-temparticipacao-recorde-de-51 porcento-nas-exportacoes-brasileiras-em-maio>. Acesso em: 20 de out de 2016.

BURREL, G, MORGAN, G. Sociological paradigms and organizational analysis: elements of the sociology of corporate life. London: Heinemann, 1979.

CALLADO, A. A. C.; CALLADO, A. L. C. Gestão de custos rurais: comparando práticas entre distintos polos de produção agroindustriais do estado de Pernambuco. Revista Contemporânea de Economia e Gestão, v. 7, n. 2, p. 65-74, 2009.

CLEGG, S. Frameworks of power. Londres: Sage, 1989.

Weber and Foucault: social theory for the study of organizations. Organization 1(1): 149-78, 1994.

Centro de Estudos Avançados em Economia Aplicada, 2016. Disponível em:〈www.cpea.esalq.usp.br/pib>. Acesso em 20 de out de 2016.

COLLIS, J.; HUSSEY, R. Pesquisa em administração: um guia prático para alunos de graduação e pós-graduação. 2. ed. Porto Alegre: Bookman, 2005.

COOPER, D. R.; SCHINDLER, P. S. Métodos de pesquisa em administração. 10. ed. Porto Alegre: Bookman, 2011.

Revista ENIAC Pesquisa, Guarulhos (SP), V.7, n.1, jan.- jun. 2018. 
CRESWELL, J. W. Projeto de pesquisa: métodos qualitativo, quantitativo e misto. Tradução Magda Lopes. 3 ed. Porto Alegre: Artmed, 2010.

DEETZ, S. Describing Difference in Approaches to Organization Science: Rethinking Burrell and Morgan and Their Legacy. Organization Science, Hanover, v. 7, n. 2, p. 191207, Apr. 1996.

FONSECA, J. J. S. Metodologia da pesquisa científica. Fortaleza: UEC, 2002.

GERHARDT, T. E., SILVEIRA, D. T. Métodos de pesquisa. Porto Alegre: Editora da UFRGS, 2009.

GIL, A. C. Como elaborar projetos de pesquisa. 4. ed. São Paulo: Atlas, 2002.

GODOY, A. S. Introdução à pesquisa qualitativa e suas possibilidades. Revista de Administração de Empresas, v. 35, n. 3, p. 20-29, 1995.

HABERMAS, J. Conhecimento e Interesse. Com um novo posfácio. Rio de Janeiro: Zahar, 1968/1982.

HAIRE, M. Modern organizationtheory. New York: Free Press, 1960.

JACKSON, N.; CARTER, P. "Paradigms Wars": A Response to Hugh Willmott. Organization Studies, London, v. 14, n. 5, p. 727-730, Sept. 1993.

KUHN, T. The structure of scientific revolutions. Chicago: University of Chicago Press, 1969.

LAW, J. Organizing modernity. Oxford: Blackwell, 1994.

LUKES, S. Power: a radical view. Londres: Macmillan, 1974.

MARTINS, H. H. T. S. Metodologia qualitativa de pesquisa. Educação e Pesquisa, v. 30, n.2, p 289-300, 2004.

PAULA, A. P. P. Beyond paradigms in Organization Studies: the Circle of Epistemic Matrices. Cad. EBAPE.BR, Rio de Janeiro, v. 14, n.1, p. 24-46, Mar. 2016. Disponível em: $\quad<$ http://www.scielo.br/scielo.php?script=sci_arttext\&pid=S1679$39512016000100024 \& \operatorname{lng}=$ en\&nrm=iso>. Acesso em 24 set. 2016.

REED, M. Teorização organizacional: um campo historicamente contestado. Handbook de Estudos Organizacionais. São Paulo: Atlas, 1999.

. The sociology of organizations. Hemel Hempstead: Harvester, 1992.

RICHARDSON, R. J. Pesquisa Social: métodos e técnicas. São Paulo: Atlas, 2008.

RODRIGUES, R. O céu é o limite para o agronegócio brasileiro. Conjuntura Econômica, Rio de Janeiro, V.60, n.11, p.1415, Nov.2006.

ROESCH, S. M. A. Projetos de Estágio e de Pesquisa em Administração: guia para

Revista ENIAC Pesquisa, Guarulhos (SP), V.7, n.1, jan.- jun. 2018. 
estágios, trabalhos de conclusão, dissertações e estudo de caso. 3. ed. São Paulo: Atlas, 2009.

SILVA, E. L; MENEZES, E. M. Metodologia da pesquisa e elaboração de dissertação. 4. ed. Florianópolis: UFSC, 2005.

TARTUCE, T. J. A. Métodos de pesquisa. Fortaleza: UNICE - Ensino Superior, 2006.

VERGARA, S. C. Projetos e relatórios de pesquisa em administração. São Paulo: Atlas, 2009.

WALDO, D. The administrative. New York: Knopf, 1948.

WAIANDT, C., FISCHER, T. O ensino dos estudos organizacionais nas instituições brasileiras: um estudo exploratório nos cursos de pós-graduação stricto sensu de administração. Administração: Ensino e Pesquisa, v. 14, n. 4, p. 785-836, dez. 2013. ISSN 2358-0917. Disponível em: <https://raep.emnuvens.com.br/raep/article/view/53/165>. Acesso em: 19 jul. 2016.

WILLIAMSON, O. K. Organization Theory: from Chester Barnard to the presente and beyond. New York: Oxford University Press, 1991.

WRONG, D. Power: its forms, bases and uses. Oxford: Basil Blackwell, 1978.

WOLIN, S. Politics and vision. Londres: Allen and Unwin, 1961.

YIN, R. K. Estudo de caso: planejamento e métodos. Porto Alegre: Bookman, 2010.

Revista ENIAC Pesquisa, Guarulhos (SP), V.7, n.1, jan.- jun. 2018. 